\title{
Study Of The Outcome Of Early And Late Rescue Surfactant Administration In Preterm Babies
}

\author{
Jayachandra Naidu $\mathrm{T}^{1}$, Kireeti $\mathrm{AS}^{2}$, Lokesh $\mathrm{B}^{3}$, Shankar Reddy Dudala ${ }^{4}$
}

${ }^{1}$ Professor, ${ }^{2}$ Associate Professor Dept of Pediatrics, ${ }^{3}$ Post graduate, Dept of Pediatrics, SV Medical College, Tirupati, A.P

${ }^{4}$ Assistant professor, Department of community medicine, SV Medical College, Tirupati, A.P.

\section{Abstract}

Introduction: Respiratory Distress Syndrome (RDS) is a common cause of mortality and morbidity in preterm. It is the commonest indication for ventilation in neonates in India. Surfactant Replacement Therapy (SRT) for RDS is a major breakthrough that has revolutionized the survival of premature infants worldwide. Randomized controlled trials have also demonstrated that prophylactic or early surfactant therapy compared with delayed surfactant treatment results in improved outcomes for preterm infants at high risk. Objective: To assess the outcome of early and late rescue surfactant administration by InSuRE (Intubation, Surfactant and Rapid Extubation) technic in managing preterm neonates with respiratory distress syndrome (RDS). Methodology: Study design: Prospective analytical study. Sample size: 144 preterm babies between 28-34 weeks of GA. Setting: Level III NICU at SVRR Government General Hospital, Tirupati, AP. Study Period: 1 year (Sep 2013 to Aug 2014). Method: All preterm babies between 28-34 weeks with respiratory distress were given surfactant with InSuRE technic immediately and categorized into early and late rescue group depending on the time of surfactant therapy i.e. within 2 hrs. of life and between 2-24 hrs. of life respectively. Results: In early rescue group there is significant reduction in mortality and lessen the need of mechanical ventilation with $p$ value $<0.05$. Conclusion: Early routine surfactant administration within $2 \mathrm{hrs}$. of life as compared to late selective administration significantly reduced the need mechanical ventilation within 7 th day of life and mortality among preterm with respiratory distress syndrome.

Keywords: Preterm, Respiratory distress syndrome, surfactant and InSuRE technic.

\section{INTRODUCTION}

Respiratory Distress Syndrome (RDS) is a common cause of mortality and morbidity in preterm. It is the commonest indication for ventilation in neonates in India. $1,2,3$. Surfactant replacement therapy (SRT) for RDS is a major breakthrough that has revolutionized the survival of premature infants worldwide ${ }^{1-4}$.

The National Neonatal Forum of India, (NNF) in 1999 published a data on 145,623 consecutively born neonates at 15 centers $^{5}$. These data show a prematurity rate of $14.5 \%$. Among the 21,125 preterm infants, there were 1,674 with the diagnosis of $\operatorname{RDS}$ ( $8 \%$ of preterm infants) accounting for $1.2 \%$ of all births. There was no information regarding the use of surfactant. Based on these data from India with annual births of 27 million, the number of preterm births can be estimated to be over 4 million/year and the annual number of infants with RDS over 300,000. The very large number of preterm births and cases of RDS pose a great challenge to clinicians and the national health planners in India ${ }^{1}$.

The main cause of the disease is inadequate production of lung surfactant. Surfactant replacement reduces mortality and morbidity rates in premature infants, reduces duration of ventilator support, number of complications and medical costs. Surfactant replacement therapy changes the natural history of RDS, resulting in up to $40 \%$ relative reduction in neonatal mortality and in 30-65\% relative reduction in risk for pneumothorax ${ }^{4}$.

Randomized controlled trials have also demonstrated that prophylactic or early surfactant therapy compared with delayed

\section{Address for correspondence* \\ Dr.A.S.KIREETI, \\ Associate Professor, Department of Pediatrics, \\ SVRR Government General Hospital, \\ Tirupati 517501. A.P. India. Email: askireeti@gmail.com}

surfactant treatment results in improved outcomes for preterm infants at high risk ${ }^{4-8,9}$.

Early administration of surfactant may prevent CPAP failure, need for ventilation ${ }^{[10-18]}$ and also reduce the duration of CPAP. In our center, all infants with RDS who do not require intubation during resuscitation and develop respiratory distress are given Rescue surfactant kept on CPAP immediately. This study was planned to evaluate the efficacy of surfactant with respect to gestational age, birth weight basis and also early routine surfactant as compared to late selective administration in infants with RDS being managed on CPAP. We hypothesized that moderate-sized preterm infants (gestation $280 / 7$ to $336 / 7$ weeks) with RDS on CPAP would have lesser need for MV in the first 7 days of life, when treated with surfactant within the first $2 \mathrm{~h}$ of life, compared with those treated late.

\section{MATERIAL AND METHODS}

A prospective analytical study conducted in all preterm babies between 28-34 weeks of gestation admitted for respiratory distress in level III Neonatal referral unit in the Department of Pediatrics, SVRR Government General Hospital, Tirupati during the period from September 2013 to August 2014. Preterm babies with perinatal asphyxia, congenital anomalies, Pneumothorax, meconium aspiration syndrome and congenital pneumonia are excluded from the study. Institutional Ethical Committee (IEC) approval was obtained prior to starting of the study. Informed consent was taken from the parents before enrolling the babies in study.

All the Preterm neonates between 28 to 34 weeks of gestation (assessment by New Ballard Score) and birth weight between 1000 to 1800 grams admitted with signs of respiratory distress as per Silverman Anderson Score included in the study duly excluding the exclusion criteria. All the babies with respiratory distress were given surfactant immediately and categorized to early and late rescue depending up on the time of surfactant therapy i.e., with in 2 hrs. of life and between 2 to $24 \mathrm{hrs}$ 
of life respectively.

Surfactant was given by InSuRE technic i.e. Surfactant was instilled directly into the lungs through the endotracheal tube under strict aseptic conditions ${ }^{17}$. Once intubated a smaller size (5 Fr) nasogastric tube cut short to the length of ETT is introduced through the ETT. The desired dose is loaded into a sterile syringe given as a bolus over $15 \mathrm{~min}$ in 2-4 aliquots. Natural surfactant (bovine) was administered in a dose of $100 \mathrm{mg} / \mathrm{kg}$ in 4 aliquots. Positive Pressure Ventilation was administered after each aliquot with self-inflating neonatal resuscitation bag with mask pressure limited to $30 \mathrm{~cm}$ of water. After completion of surfactant administration if oxygen saturations were maintained [87-93\%] neonate was extubated back to CPAP [InSuRE].

Adjustment in continuous distending pressure was based on chest retractions, and SPO2 with maximum pressures limit of $7 \mathrm{~cm}$ of water. FiO2 was adjusted to maintain SPO2 between $87-$ $93 \%$. When the infant was stable on CPAP pressure of $4 \mathrm{~cm}$ with $\mathrm{FiO} 2<0.25$ for $8-12$ hours, CPAP was discontinued and infant was shifted to head box oxygen. Post procedure babies were monitored based on Silverman Anderson score with respect to need of oxygen / need of CPAP / mechanical ventilation.

CPAP Success criteria: Reduced need for CPAP depends on decreased oxygen requirement and clinical improvement in Silver Man Anderson score i.e. less than 3/10. Above two lead to successful stoppage of CPAP.

CPAP failure criteria: Worsening of respiratory distress, Rise in FiO2 $>0.6$, CPAP needs above $8 \mathrm{~cm}$ of water, Shock, more than 2 episodes of apnoea requiring positive pressure ventilation. Those neonates who fit in CPAP failure criteria were intubated and mechanically ventilated.

OUTCOME: Immediate response at 6 th $\mathrm{hr}$ of surfactant administration: No oxygen requirement / Need of non-invasive respiratory support (CPAP) after extubation / Need of mechanical ventilation / pulmonary haemorrhage / Shock / Death.

Secondary outcome was assessed in terms of following parameters: Need of mechanical ventilation within day 7 of life, duration on CPAP in hrs median, duration on mechanical ventilation in hours, pneumothorax, PDA, culture positive sepsis, IVH, oxygen dependence at 28 days of life, oxygen dependence at 36 weeks of life.

Neonatal data was collected using predesigned and pretested proforma. The results for each parameter were presented in tables and charts. Statistical Data analysis was carried out using MS excel, EPI - info 3.5.1 version. For determining significance of each test $p$ value was used. The $p$ value of less than 0.05 was accepted as indicating statistical significance.

\section{RESULTS}

Total 144 preterm babies with respiratory distress were given surfactant by InSuRE technic. Majority of preterm in present study group had a birth weight of 1500-1799gms (40\%), those between 1250-1499gms are (36.7\%) and those between 1000-1249 accounting for $23.30 \%$.
Table-1: Distribution of cases according to birth weight

\begin{tabular}{|c|c|c|}
\hline Birth wt. In grams & No. of cases $(\mathbf{n = 1 4 4})$ & Percentage (\%) \\
\hline $1000-1249$ & 33 & 23.3 \\
\hline $1250-1499$ & 53 & 36.7 \\
\hline $1500-1799$ & 58 & 40 \\
\hline
\end{tabular}

Majority of the preterm in present study lie between 32-34 Wks.

\section{OUTCOME}

Table -3: Mortality In Relation With Early Rescue And Late Rescue Surfactant Treated Babies

\begin{tabular}{|c|c|c|}
\hline $\begin{array}{c}\text { Time in Hour } \\
\text { of Surfactant } \\
\text { Administration }\end{array}$ & $\begin{array}{c}\text { No. of } \\
\text { Cases }\end{array}$ & Deaths \\
\hline$<2 \mathrm{HR}$ & 49 & $13(26.5 \%)$ \\
\hline$>2 \mathrm{HR}$ & 95 & $45(47.3 \%)$ \\
\hline
\end{tabular}

Above table shows incidence of mortality is high in late rescue surfactant treated babies accounting 45 deaths of 95 cases (47.3\%) compared to early rescue group 13 deaths out of 49 cases $(26.5 \%)$. significant difference exits between the two groups with $\mathrm{p}$ value $<0.05$.

Table-2: Distribution of cases according to gestational age

\begin{tabular}{|c|c|c|}
\hline Gestational age & $\begin{array}{c}\text { No. of cases } \\
(\mathbf{n = 1 4 4})\end{array}$ & $\begin{array}{c}\text { Percentage } \\
(\boldsymbol{\%})\end{array}$ \\
\hline $28-30$ wks. & 38 & 26.6 \\
\hline $30-32$ wks. & 46 & 31.6 \\
\hline $32-34$ wks. & 60 & 41.6 \\
\hline
\end{tabular}

No. of preterm new born babies those who received surfactant within 2 hours of life i.e., early rescue were 49 babies (34\%) and 95 babies $(66 \%)$ received more than 2 hours after birth but within 24 hrs of life.

\section{SECONDARY OUTCOME}

INCIDENCE OF VARIOUS PARAMETERS IN EARLY AND LATE RESCUE

Table 4: Assessment of outcome in early vs late rescue

\begin{tabular}{|c|c|c|}
\hline & $\begin{array}{c}\text { Early rescue } \\
(\mathbf{n = 4 9})\end{array}$ & $\begin{array}{c}\text { Late rescue } \\
(\mathbf{n = 9 5})\end{array}$ \\
\hline $\begin{array}{c}\text { Need of } \\
\text { mechanical } \\
\text { ventilation } \\
\text { within 7 days of } \\
\text { life }\end{array}$ & $14(28.5 \%)$ & $50(52.6 \%)$ \\
\hline
\end{tabular}


14 cases out of 49 cases corresponding to $28.5 \%$ required mechanical ventilation which is significantly low in early rescue group compared to 50 cases out of 95 accounting for 52.6 in late rescue group. Significant difference exists between the two groups with $p$ value $<0.05$.

Table 5: Mean duration of Mechanical vs CPAP ventilation

\begin{tabular}{|c|c|c|}
\hline & $\begin{array}{c}\text { EARLY } \\
\text { RESCUE } \\
(\mathrm{n}=49)(34 \%)\end{array}$ & $\begin{array}{c}\text { LATE RESCUE } \\
(\mathrm{n}=95)(66 \%)\end{array}$ \\
\hline $\begin{array}{c}\text { Duration on } \\
\text { Mechanical } \\
\text { Ventilation In } \\
\text { Hours (Mean) }\end{array}$ & 42.5 & $59 \mathrm{hrs}$ \\
\hline $\begin{array}{c}\text { Duration on } \\
\text { CPAP in Hrs. } \\
\text { Median }\end{array}$ & 30.6 & $44 \mathrm{hrs}$ \\
\hline
\end{tabular}

Mean duration of mechanical ventilation $42.5 \mathrm{hrs}$. in early rescue group $59 \mathrm{hrs}$. when compared to late rescue group. Whereas CPAP on early rescue group is 30.6 which is low in early rescue group compared to late rescue group.

2 out of 49 cases of early rescue group and 6 out of 95 cases of late rescue group developed Pneumothorax which has no significant difference exists.

Preterm out of 49 cases, $16.3 \%$ had culture positive sepsis compared to late rescue group of $34.2 \%$, which is significantly high reason may be duration of mechanical ventilation, CPAP, were high in late rescue group compared to early rescue group.

3 cases out of 49 cases (6.1\%) were dependent on oxygen at 28 days of life in early rescue group compared to 15 cases out of 95 cases (15.7\%) in late rescue group.

At 36 weeks of life 1 case out of 49 cases (2.0) was on oxygen requirement compared to 6 cases out of 95 cases

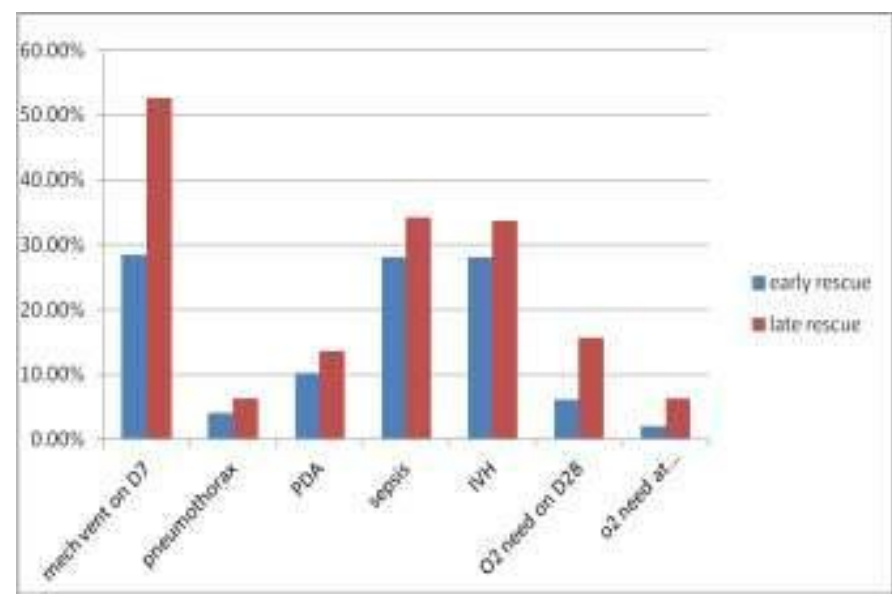

Figure 1: Incidence of Secondary Outcome In Early And Late Rescue

It can be seen from the above bar diagram that need for mechanical ventilation and thereby incidence of sepsis was significantly higher in late rescue therapy when compared to early rescue therapy. Incidence of complications like pneumothorax, PDA, IVH, CLD were also higher in late rescue therapy when compared to early rescue therapy.

\section{DISCUSSION}

Respiratory distress due to various causes afflicts 5$12 \%$ of neonates in our country. Hyaline membrane disease is a major cause of respiratory distress in preterm new born. The incidence of Hyaline membrane disease is reported to be $6.8 \%$ to $14.1 \%$ of preterm live births in our country. At gestational ages of 29-30 wks., the incidence is as high as $32 \%$ while at 28 weeks, the incidence is not well documented.

HMD is the commonest indication of ventilation in neonates in our country. The reported survival of babies ventilated for HMD has varied from $25 \%$ to $64 \%$ in our country. 
Table 6: Distribution of cases as per gestational age

\begin{tabular}{|c|c|c|}
\hline $\begin{array}{c}\text { Gestational } \\
\text { age }\end{array}$ & $\begin{array}{c}\text { Present } \\
\text { study } \\
(\%)\end{array}$ & $\begin{array}{c}\text { Anil Narang et } \\
\text { al. (\%) }\end{array}$ \\
\hline 28-30 wks. & 26.6 & 18 \\
\hline $30-32$ wks. & 31.6 & 22.7 \\
\hline $32-34$ wks. & 41.6 & 35.2 \\
\hline
\end{tabular}

In the present study, incidence is high in all age groups when compared to Anil Narang et al., reason for high incidence could be due to less administration of antenatal steroid $24 \mathrm{hrs}$. prior to delivery which decreases incidence of RDS.

Table 7: Distribution of cases as per birth weight

\begin{tabular}{|c|c|c|}
\hline $\begin{array}{c}\text { Birth wt. In } \\
\text { grams }\end{array}$ & $\begin{array}{c}\text { Present } \\
\text { study (\%) }\end{array}$ & $\begin{array}{c}\text { Anil Narang et } \\
\text { al (\%) }\end{array}$ \\
\hline $1000-1249$ & 23.3 & 24 \\
\hline $1250-1499$ & 36.7 & 28.4 \\
\hline $1500-1749$ & 40 & 28.4 \\
\hline
\end{tabular}

Incidence Respiratory distress in babies with birth weight 1000-1249 grams was observed as 23.3\% in present study compared to $24 \%$ in a study of Anil Narang et al which is almost same in both studies. Among 1250-1499 grams group it was $36.7 \%$ in present study and $28.4 \%$ in Anil Narang et al. 40 $\%$ of incidence was noted in babies of birth weight 1500-1749.

Incidence of RDS is higher in 1250 to $1800 \mathrm{gms}$ in present study which can be explained by decreased number of booked cases and decreased administration of antenatal steroids prior to delivery.

Table 8 :Distribution of cases according to time of surfactant administration

\begin{tabular}{|c|c|c|}
\hline $\begin{array}{c}\text { Age in hrs. at } \\
\text { which } \\
\text { surfactant } \\
\text { received }\end{array}$ & Percentage (\%) & $\begin{array}{c}\text { Hemasree et } \\
\text { al., }\end{array}$ \\
\hline $\begin{array}{c}<2 \text { hrs (early } \\
\text { rescue) }\end{array}$ & 34 & 48.4 \\
\hline $\begin{array}{c}>2 \text { hrs (late } \\
\text { rescue) }\end{array}$ & 66 & 51.6 \\
\hline
\end{tabular}

Above table shows the percentage of cases who received surfactant with in $2 \mathrm{hrs}$ of life which is $34 \%$ in early rescue in the present study and in Hemasree et al., it is $48.4 \%$. While in late rescue it is $66 \%$ in the present study where as it is $51.6 \%$ in
Hemasree et al. Number of cases in early rescue is low when compared to Hemasree et al., which is a limitation in the present study.

Table 9: Mortality In Relation To Gestational Age

\begin{tabular}{|c|c|c|}
\hline $\begin{array}{c}\text { Gestational } \\
\text { age }\end{array}$ & $\begin{array}{c}\text { Present } \\
\text { study } \\
(\boldsymbol{\%})\end{array}$ & $\begin{array}{c}\text { Anil } \\
\text { Narang et } \\
\text { al (\%) }\end{array}$ \\
\hline 28-30 weeks & 50 & 50 \\
\hline $30-32$ weeks & 39.1 & 35 \\
\hline $32-34$ weeks & 35 & 26 \\
\hline
\end{tabular}

Mortality was higher among 28-30 wks. gestational age group in the present study $(50 \%)$ which is comparable to $50 \%$ in a study by Anil Narang et al. Between 30-32 weeks it is $39.1 \%$ which is slightly more when compared to Anil Narang et al.

Mortality among 32-34 wks. Gestational age group in present study was $35 \%$ which is higher compared to $26 \%$ in a study by Anil Narang et al.

Reason for higher mortality in present study could be explained by the observation that incidence of unbooked pregnancies and perinatal complications are high. And also the incidence of PROM is more in present study which is an additive factor for increased incidence of sepsis leading to higher mortality

Table 10 : Mortality In Relation To Birth Weight

\begin{tabular}{|c|c|c|}
\hline BIRTH WEIGHT & DEATHS & Huanhuan et al $^{\mathbf{1 9}}$ \\
\hline $1000-1249$ & $54.5 \%$ & 44.1 \\
\hline $1250-1499$ & $40 \%$ & 26.4 \\
\hline $1500-1799$ & $36 \%$ & 13 \\
\hline
\end{tabular}

Mortality was higher(54.5\%) among babies with birth weight 1000-1249 grams in present study compared to $44.1 \%$ in a study by Huanhuan et al. Between 1250-1499 grams there is $40 \%$ mortality which is significantly higher when compared to Huanhuan et al.,

Mortality among 1500-1799 weight group was much higher $(36.2 \%)$ when compared to a study by Huanhuan et al., which is only $13 \%$.

Table 11 : Mortality Of Early Rescue Surfactant Administration

\begin{tabular}{|c|c|c|}
\hline Outcome & $\begin{array}{c}\text { Present } \\
\text { Study } \\
(\%)\end{array}$ & $\begin{array}{c}\text { Hemasree } \\
\text { et al }^{\mathbf{1 5}}\end{array}$ \\
\hline Survival & 71.5 & 87.8 \\
\hline Deaths & 28.5 & 12.2 \\
\hline
\end{tabular}


Survival rate among babies who were administered early rescue surfactant was $71.5 \%$ in present study when compared to a much higher survival rate $(87.8 \%)$ in a study by Hemasree et al.

Table 12: Mortality Of Late Rescue Surfactant Administration

\begin{tabular}{|c|c|c|c|c|}
\hline Outcome & $\begin{array}{c}\text { Present } \\
\text { Study } \\
(\%)\end{array}$ & $\begin{array}{c}\text { Hemasree } \\
\text { et al }^{15}\end{array}$ & $\begin{array}{l}\text { Verder } \\
\text { et al }^{\angle 0}\end{array}$ & $\begin{array}{c}\text { Reininger } \\
\text { et al }^{\top}\end{array}$ \\
\hline Survival & 53.7 & 86.1 & 57 & 50 \\
\hline Deaths & 46.3 & 13.9 & 43 & 50 \\
\hline
\end{tabular}

Survival rate was lesser among babies administered with late rescue surfactant which is $53.7 \%$ when compared to early rescue surfactant in present study which is $71.5 \%$.

Survival rate is $53.7 \%$ in the late rescue group which is almost similar to Verder et al., and Reininger et al., is less when compared to Hemasree et al., But in a study by Hemasree et al, survival rate was almost equal among babies administered early and late rescue surfactant.
This may be due to other factors like PDA, IVH, and culture positive sepsis.

$6.1 \%$ of babies born before 32 wks. Gestational age were oxygen dependent on 28th day of life in present study compared to $2.7 \%$ in a study by Hemasree et al.

$2.0 \%$ babies born $>32$ wks. Gestational age were oxygen dependent at 36 wks. of life in present study whereas none were oxygen dependent in a study by Hemasree et al. higher incidence of oxygen dependency may be due to increased requirement of mechanical ventilation which affects the outcome of present study.

In a study by Verder et al, 37\% babies were oxygen dependent at 28 days of life which was much higher compared to present study.

$52.6 \%$ cases who were given late rescue surfactant needed mechanical ventilation within 7 days of life compared to $27 \%$ of early rescue surfactant babies in present study.

Percentage of babies who were oxygen dependent at 28 days of life was higher after late rescue surfactant in present study when compared to study by Hemasree et al., and Verder et al., which could be explained by increased need of mechanical

Table 16 : Secondary Outcome Of Early Resue Surfactant Administration

\begin{tabular}{|c|c|c|c|}
\hline Outcome & $\begin{array}{c}\text { Present } \\
\text { study } \\
\text { n =144 (\%) }\end{array}$ & $\begin{array}{l}\underset{13}{\text { Hemasri et }} \\
\text { al. } \\
(\%)\end{array}$ & $\begin{array}{c}\text { Verder et al. } \\
(\%)\end{array}$ \\
\hline $\begin{array}{l}\text { 1. Need of Mechanical Ventilation Within Day } 7 \\
\text { of Life }\end{array}$ & $13(26.5 \%)$ & 16.2 & 21 \\
\hline 2.Duration on CPAP in Hrs. (Median) & 30.6 & 24 & 38.5 \\
\hline $\begin{array}{l}\text { 3.Duration on Mechanical Ventilation in Hours } \\
\text { (median) }\end{array}$ & 42.5 & 32.5 & 60 \\
\hline 4.Pneumothorax & $2(4.1 \%)$ & 1.9 & 0 \\
\hline 5.PDA & $5(10.2 \%)$ & 27 & 30 \\
\hline 6.Culture Positive Sepsis & $8(16.3 \%)$ & 24.3 & 15 \\
\hline 7.IVH & $3(6.1 \%)$ & 4.1 & 3 \\
\hline 8.Oxygen Dependent at 28 Days of Life & $3(6.1 \%)$ & 2.7 & 37 \\
\hline 9. Oxygen Dependent at 36 Weeks of Life & $1(2.0 \%)$ & 0 & 3 \\
\hline
\end{tabular}

Secondary outcome was assessed in the form of factors affecting the success of surfactant (Early and late rescue) and duration of oxygen dependency and need for mechanical ventilation.

In present study, 13 cases out of 49 cases accounting for $26.5 \%$ cases needed mechanical ventilation within 7 days of life, which is higher compared to $16.2 \%$ in a study by Hemasree et al. ventilation in the present study.

Incidence of PDA, culture positive sepsis, IVH, prolonged need of mechanical ventilation was higher among babies who were given late rescue surfactant in present study. 
Table 17 : Secondary Outcome Of Late Rescue Surfactant Administration

\begin{tabular}{|l|c|c|c|}
\hline & $\begin{array}{c}\text { Present } \\
\text { Study }\end{array}$ & $\begin{array}{c}\text { Hemasri et } \\
\text { al. }\end{array}$ & $\begin{array}{c}\text { Verder et } \\
\text { al. }\end{array}$ \\
\hline $\begin{array}{l}\text { 1. Need of Mechanical Ventilation within day 7 of } \\
\text { Life (\%) }\end{array}$ & $50(52.6)$ & 31.6 & 63 \\
\hline $\begin{array}{l}\text { 2.Duration on CPAP in Hrs } \\
\text { Median }\end{array}$ & 44 & 28 & 39 \\
\hline $\begin{array}{l}\text { 3.Duration on Mechanical Ventilation in Hours } \\
\text { (median) }\end{array}$ & 59 & 42 & 50.4 \\
\hline 4.Pneumothorax & $6(6.3 \%)$ & 2.3 & 0 \\
\hline 5.PDA & $13(13.6 \%)$ & 30.4 & 59 \\
\hline 6.Culture Positive Sepsis & $32(34.2 \%)$ & 17.7 & 19 \\
\hline 7.IVH & $8(8.4 \%)$ & 3.8 & 0 \\
\hline 8.Oxygen Dependent at 28 Days of Life & $15(15.7 \%)$ & 8.9 & 40 \\
\hline 10.Oxygen Dependent at 36 Weeks of Life & $6(6.3 \%)$ & 2.5 & 4 \\
\hline
\end{tabular}

\section{CONCLUSIONS}

Through InSuRE technic there was reduction in mortality among preterm with respiratory distress syndrome with increase in gestational age and birth weight. Early rescue surfactant administration within $2 \mathrm{hrs}$ of life as compared to late selective administration significantly reduced the need of mechanical ventilation in the first week of life and mortality among preterm infants with respiratory distress syndrome.

Conflict of interest: None

Role of funding source: None

\section{REFERENCES}

1. Kumar P, Kumar R, Narang A. Spectrum of neonatal respiratory distress at PGI. Bull NNF 1999; 13: 8-12.

2. Bhakoo ON. Assisted ventilation in neonates: The Indian perspective. Indian Pediatr 1995; 32: 1261-64.

3. Nangia S, Saili A, Dutta AK, Gaur V, Singh M, Seth A, Kumari S. Neonatal mechanical ventilation-experience at a level II care centre. Indian $\mathrm{J}$ Pediatr.1998; 65:291-96.

4. AARC Clinical Practice Guideline. Surfactant Replacement Therapy. Respir Care 1994; 39:824-29.

5. Stevens TP, Harrington EW, Blennow M, Soll RF: Early surfactant administration with brief ventilation vs selective surfactant and continued mechanical ventilation for preterm infants with or at risk for respiratory distress syndrome. Cochrane Database Syst Rev 2007:CD003063.
6. Sandri F, Plavka R, Ancora G, Simeoni U, Stranak Z, Martinelli S, Mosca F, Nona J, Thomson M, Verder H, Fabbri L, Halliday H, CURPAP Study Group: Prophylactic or early selective surfactant combined with nCPAP in very preterm infants. Pediatrics 2010; 125:e1402-e1409.

7. Reininger A, Khalak R, Kendig JW: Surfactant administration by transient intubation in infants 29 to 35 weeks' gestation with respiratory distress syndrome decreases the likelihood of later mechanical ventilation: a randomized controlled trial. J Perinatol 2005; 25: 703-708.

8. Sweet D, Bevilaqua G, Carnielli V, et al.European consensus Guidelines in the management of Neonatal Respiratory distress syndrome. J Perinat Med 2007; 35:175-186.

9. Enhorning G, Shennon A, Possmayer F, et al. Prevention of Neonatal respiratory distress syndrome by Tracheal instillation of Surfactant:A randomized clinical trial. Pediatrics 1985; 76:145-153.

10. Yost CC, Soll RF. Early vs delayed selective surfactant treatment for neonatal respiratory distress syndrome.Cochrane Database Syst Rev. 2000; 2:CD001456.

11. Ho JJ, Henderson Smart DJ, Davis PG. Early vs delayed initiation of continuous distending pressure for respiratory distress syndrome in preterm infants. Cochrane database Syst Rev 2002; 2:CD002975.

12. Anil Narang, Praveen Kumar et al., - Surfactant therapy 
for hyaline membrane disease .Indian Pediatrics 2001; 38:640-646.

13. Hemasree Kandraju a Srinivas Murki a Sreeram Subramanian a Pramod Gaddam a Ashok Deorari b Praveen Kumar c. Early Routine versus Late Selective Surfactant in Preterm Neonates with Respiratory Distress Syndrome on Nasal Continuous Positive Airway Pressure: A Randomized Controlled Trial. Neonatology 2013; 103:148-154.

14. Dani, C., Bertini, G., Pezzati, M., Cecchi, A., Caviglioli, C., \& Rubaltelli, F. F. (2004). Early extubation and nasal continuous positive airway pressure after surfactant treatment for respiratory distress syndrome among preterm infants $<30$ weeks' gestation. Pediatrics, 113(6), e560-3.

15. Bahadue, F. L., \& Soll, R. (2012). Early versus delayed selective surfactant treatment for neonatal respiratory distress syndrome . Cochrane Database of $\mathrm{S}$ y s $\mathrm{t}$ e $\mathrm{m}$ a t i c R e vi e w s ( O n 1 i n e ), 11 , CD001456.doi:10.1002/14651858.CD001456.pub2;0. 1002/ 14651858. CD001456.pub2

16. Escobedo, M. B., Gunkel, J. H., Kennedy, K. A., Shattuck, K. E., Sanchez, P. J., Seidner, S., Texas Neonatal Research Group. (2004). early surfactant for neonates with mild to moderate respiratory distress syndrome: A multicentre, randomized trial. The Journal of P e diatri c s, 144 ( 6 ), , $804-808$. doi:10.1016/j.jpeds.2004.03.024.
17. Dani, C., Corsini, I., Bertini, G., Fontanelli, G., Pratesi, S., \& Rubaltelli, F. F. (2010). The InSuRE method in preterm infants of less than 30 weeks' gestation. The Journal of Maternal-Fetal \& Neonatal Medicine : The Official Journal of the European Association of Perinatal Medicine, the Federation of Asia and Oceania Perinatal Societies, the International Society of Perinatal O b s te tri c i a n s, 23(9), $1024-10$ 2 9. D o i : $10.3109 / 14767050903572174$.

18. Soll, R. F., \& Morley, C.J. (2001). Prophylactic versus selective use of surfactant in preventing morbidity and mortality in preterm infants. Cochrane Database of Systematic Reviews (Online), (2)(2), CD000510. doi:10.1002/14651858.CD000510.

19. Huanhuan MDd, Xinzhu Lin, MDe, Changyi Yang, MDf, Zhenlang Lin, MDg, Wenjun Zhu, MDh, Zhenying Yang, MDi, Fengqin Yu, MDj, Yinping Qiu, MDk, Xianzhi Liu, MDl, Xiaoyu Zhou, MDm, Chao Chen, MDa, Bo Sun, MDa, and on behalf of the Chinese Collaborative Study Group for Neonatal Respiratory Diseases. Morbidity and Mortality of Neonatal Respiratory Failure in China: Surfactant Treatment in Very Immature Infants. American Academy of PediatricsPublished online February 13, 2012(doi: 10.1542/peds.2011-0725)

20. Verder H, Albertsen P, Ebbesen F: Nasal continuous positive airway pressure and early surfactant therapy for respiratory distress syndrome in newborns of less than 30 weeks' gestation. Pediatrics 1999; 103:E24. 